\title{
Factors influencing patient choice of dialysis versus conservative care to treat end-stage kidney disease
}

\author{
Rachael L. Morton PhD, Paul Snelling MBChB, Angela C. Webster MBBS PhD, John Rose PhD, \\ Rosemary Masterson MBBS PhD, David W. Johnson MBBS PhD, Kirsten Howard PhD
}

\begin{abstract}
Background: For every patient with chronic kidney disease who undergoes renalreplacement therapy, there is one patient who undergoes conservative management of their disease. We aimed to determine the most important characteristics of dialysis and the trade-offs patients were willing to make in choosing dialysis instead of conservative care.
\end{abstract}

Methods: We conducted a discrete choice experiment involving adults with stage 3-5 chronic kidney disease from eight renal clinics in Australia. We assessed the influence of treatment characteristics (life expectancy, number of visits to the hospital per week, ability to travel, time spent undergoing dialysis [i.e., time spent attached to a dialysis machine per treatment, measured in hours], time of day at which treatment occurred, availability of subsidized transport and flexibility of the treatment schedule) on patients' preferences for dialysis versus conservative care.
Results: Of 151 patients invited to participate, 105 completed our survey. Patients were more likely to choose dialysis than conservative care if dialysis involved an increased average life expectancy (odds ratio [OR] 1.84, 95\% confidence interval $[\mathrm{Cl}] 1.57-2.15)$, if they were able to dialyse during the day or evening rather than during the day only (OR $8.95,95 \% \mathrm{Cl} 4.46-$ 17.97), and if subsidized transport was available (OR 1.55, 95\% Cl 1.24-1.95). Patients were less likely to choose dialysis over conservative care if an increase in the number of visits to hospital was required (OR $0.70,95 \% \mathrm{Cl} 0.56-0.88$ ) and if there were more restrictions on their ability to travel (OR $=0.47,95 \% \mathrm{Cl} 0.36-0.61$ ). Patients were willing to forgo 7 months of life expectancy to reduce the number of required visits to hospital and 15 months of life expectancy to increase their ability to travel.

Interpretation: Patients approaching endstage kidney disease are willing to trade considerable life expectancy to reduce the burden and restrictions imposed by dialysis.
$\mathrm{S}$ tage 5 chronic kidney disease is a major health issue worldwide and has a mortality that exceeds many cancers. ${ }^{1,2}$ The treatment options for stage 5 (i.e., end-stage) kidney disease include dialysis, kidney transplantation and supportive nondialytic treatment (conservative care). A national report by the Australian Institute of Health and Welfare estimates that for every patient with chronic kidney disease who undergoes dialysis or transplantation, there is one other patient whose disease is managed conservatively. ${ }^{3}$

Conservative care includes the multidisciplinary management of uremic symptoms through diet and medications, such as erythropoietin and diuretics, as well as psychosocial support and eventual palliative care. The reported median survival with conservative care for end-stage kidney disease is between 6 and 32 months. For some patients, particularly the elderly and those with ischemic heart disease, this period may be equal to or greater than their expected survival with dialysis.. ${ }^{4-7}$ Dialysis usually prolongs life, but it can impose a substantial burden on patients and their families and may be associated with a reduction in quality of life. The decision to start dialysis thus involves an assessment of both the evidence-based outcomes for the population in question and the preferences of the individual patient.

Incorporating patient preferences for treatment of stage 5 chronic kidney disease is recommended in clinical guidelines; ${ }^{8}$ however, little is known about the trade-offs that patients are willing to consider when choosing between dialysis and conservative care. Discrete choice experiments are used to quantify patient preferences. These experiments are grounded in economic theory ${ }^{9,10}$ and allow the measurement of patients' strengths of preferences for different characteristics of treatment and the trade-offs involved. Real-world decisions are closely simulated
Competing interests:

David Johnson is a consultant for Baxter

Healthcare and has received speakers' honoraria, travel sponsorships and research grants from this organization; he has received research grants from Fresenius Medical Care; he was a consultant for Gambro. No other competing interests were declared.

This article has been peer reviewed.

Correspondence to: Rachael L. Morton, rachael.morton@sydney .edu.au

CMAJ 2012. DOI:10.1503 /cmaj.111355 
through the simultaneous consideration of all treatment characteristics. ${ }^{11}$ Discrete choice experiments are a valid and reliable approach to eliciting preferences for health care ${ }^{12-14}$ and have been used to measure the preferences of patients with chronic kidney disease in terms of organ donation and allocation, and end-of-life care. ${ }^{15}$

Knowing patients' preferences for the treatment of stage 5 chronic kidney disease is necessary to plan appropriate health care services and enhance the quality of care. With this study, we aimed to quantify the extent to which the characteristics of dialysis influence patient preferences for treatment and to assess the trade-offs patients were willing to make between these characteristics.

\section{Methods}

\section{Patients}

English-literate patients with chronic kidney disease (stages 3-5) aged 18 years and older were eligible for our study. Of these patients, we included those who had received information about dialysis and conservative care. We also included patients with a failing kidney transplant who were approaching dialysis. Patients with cognitive impairments, as determined by their treating clinicians, were excluded.

The study was approved by the ethics committee of each of the hospitals involved and was conducted according to the Declaration of Helsinki.

\section{Data collection}

We performed a discrete choice experiment involving eligible patients from eight Australian metropolitan and rural renal clinics. Data were collected between October 2010 and February 2011. Patients were invited to participate in the study by the principal researcher (Rachael Morton), by their nephrologist or by their renal unit's chronic kidney disease coordinator. After giving their informed consent, patients received the survey and completed it either in the renal clinic or at their homes. Completed surveys were returned by prepaid mail.

\section{Discrete choice experiment}

The methods used followed published guidelines for conducting discrete choice experiments in health. ${ }^{11,12,14}$ We used an unlabelled choice survey with 12 questions (the choice sets) comprising two dialysis alternatives (peritoneal dialysis and hemodialysis) and one fixed "no dialysis" alternative. The selection of characteristics and levels was based on previous studies, including a systematic review of the literature, ${ }^{16}$ a qualitative analysis of interviews with patients receiving dialysis ${ }^{17}$ and a ranking exercise. ${ }^{18}$ We determined levels for life expectancy and time spent undergo- ing dialysis from international registry data ${ }^{1,19,20}$ to encompass the range of plausible values (Box 1). We used data from observational studies involving patients whose disease was managed conservatively to inform the characteristics of the "no dialysis" alternative..$^{47}$ We also considered local policy initiatives from government dialysis plans, such as subsidized patient transport. ${ }^{21}$

\section{Survey design}

We created a D-efficient design, ${ }^{22}$ which required a sample size of 100 patients to estimate a main-

\section{Box 1: Characteristics of treatment} analyzed in the discrete choice experiment and their accompanying levels

- Average life expectancy, yr

- 2*

$-5$

- 10

- 15

- Visits to hospital for dialysis, no./wk

- 0 *†

$-2$

$-3$

- 4

- Ability to travel or take short trips

- Not restricted*

- Slightly restricted (no more than 7 nights away)

- Very restricted (only 1 night away)

- Time spent undergoing dialysis, hoursł

- 0 *

$-4$

$-8$

$-10$

- Time of day dialysis can be done

- Day*

- Day or evening

- Night (nocturnal)

- Not applicable

- Subsidized transport provided for attending treament or appointments

- Not provided*

- Provided at small cost to me

- Provided at no cost to me

- Ability to change day or time of dialysis

- Not applicable*

- Up to once per month

- Up to once per week

- Whenever necessary

*Reference group.

tDenotes conservative care or dialysis performed at home. $¥$ Refers to the time for which a patient was connected to a dialysis system or machine. 
effects model. D-efficient designs optimize the combination of attribute levels, in as few choice sets as possible, to obtain the most meaningful data about respondents' choices (Appendix 1, available at www.cmaj.ca/lookup/suppl/doi:10 .1503/cmaj.111355/-/DC1).

The survey included a preamble with relevant contextual information; an explanation of each characteristic and its levels; a practice question; 12 choice sets; sociodemographic questions on age, sex, employment status, health insurance and equivalized household income; ${ }^{23}$ and questions about the stage of the patient's disease, previous kidney transplants and distance from the patient's home to the renal unit. A full copy of the survey is in Appendix 2 (available at www.cmaj.ca /lookup/suppl/doi:10.1503/cmaj.111355/-/DC1).

We pilot-tested the survey in interviews with 30 patients with chronic kidney disease to assess their interpretation of the questions and ability to complete the task.

\section{Statistical analysis}

We used mixed logit (random parameters logit) models (Appendix 1) to perform all analyses..$^{14,24}$

We combined both dialysis alternatives to assess the preferences for dialysis compared with conservative care. An odds ratio (OR) greater than 1.00 for a characteristic suggested that, as the level of the characteristic increased, dialysis was preferred over conservative care; an OR less than 1.00 suggested that, as the levels increased, conservative care was preferred over dialysis.

Sociodemographic data were incorporated into the model as separate characteristics and as interaction terms to explore possible sources of heterogeneity. We tested the model's internal validity (i.e., the extent to which results were consistent with a priori expectations) by examining the signs and significance of parameter estimates. A priori, we expected patients to prefer longer life expectancy, less time per treatment, unrestricted travel, greater flexibility in treatment schedules, dialysis delivered overnight and the availability of subsidized transport. We expected an interaction between older age and preference for conservative care. We calculated the benefit-to-harm trade-offs that patients were willing to accept between characteristics of dialysis using the ratios of the mean parameter estimates. We collated the descriptive comments provided by patients to help understand the rationale behind their choices.

\section{Results}

Of 151 eligible patients who were invited to participate, $105(69.5 \%)$ completed our survey. Patient characteristics are reported in Table 1.
Table 1: Baseline characteristics of the study participants

\begin{tabular}{|c|c|}
\hline Characteristic & $\begin{array}{l}\text { Participants, no. }(\%) * \\
n=105\end{array}$ \\
\hline Age, yr, median (IQR) & $63(55-71)$ \\
\hline \multicolumn{2}{|l|}{ Age group, yr } \\
\hline$<45$ & $11(10.5)$ \\
\hline $45-54$ & $14(13.3)$ \\
\hline $55-64$ & $35(33.3)$ \\
\hline $65-74$ & $31(29.5)$ \\
\hline $75-84$ & $14(13.3)$ \\
\hline \multicolumn{2}{|l|}{ Sex } \\
\hline Male & $59(56.2)$ \\
\hline Female & $46(43.8)$ \\
\hline \multicolumn{2}{|l|}{ Health insurance } \\
\hline Public & $58(55.2)$ \\
\hline Private & $46(43.8)$ \\
\hline Unknown & $1(0.9)$ \\
\hline \multicolumn{2}{|l|}{ Level of education } \\
\hline Primary school & $9(8.6)$ \\
\hline Secondary school & $50(47.6)$ \\
\hline Postsecondary & $46(43.8)$ \\
\hline \multicolumn{2}{|l|}{ Employment status } \\
\hline Retired with pension & $62(59.0)$ \\
\hline Self-funded retirement & $11(10.5)$ \\
\hline Part-time & $8(7.6)$ \\
\hline Full-time & $15(14.3)$ \\
\hline Unemployed & $3(2.9)$ \\
\hline Home duties & $6(5.7)$ \\
\hline \multicolumn{2}{|l|}{ Distance from home to dialysis unit, $\mathrm{km}$} \\
\hline $0-10$ & $36(34.3)$ \\
\hline $11-50$ & $51(48.6)$ \\
\hline $51-100$ & $8(7.6)$ \\
\hline$>100$ & $8(7.6)$ \\
\hline Unknown & $2(1.9)$ \\
\hline \multicolumn{2}{|l|}{ No. of people in household } \\
\hline 1 & $26(24.8)$ \\
\hline 2 & $50(47.6)$ \\
\hline$\geq 3$ & $29(27.6)$ \\
\hline \multicolumn{2}{|l|}{ Household income } \\
\hline Low & $73(69.5)$ \\
\hline Middle & $6(5.7)$ \\
\hline High & $10(9.5)$ \\
\hline Did not report & $16(15.2)$ \\
\hline eGFR, mL/min per $1.73 \mathrm{~m}^{2}$, mean (range) & $18.1(6-34)$ \\
\hline \multicolumn{2}{|l|}{ Stage of disease, eGFR, $\mathrm{mL} / \mathrm{min}$ per $1.73 \mathrm{~m}^{2}$} \\
\hline $3-4(e G F R \geq 15)$ & $49(46.7)$ \\
\hline 5 (eGFR <15) & $56(53.3)$ \\
\hline Previous kidney transplant & $5(4.8)$ \\
\hline
\end{tabular}


The median age was 63 years (interquartile range 55-71 years) and the mean estimated glomerular filtration rate (eGFR) was 18.1 (range 634) $\mathrm{mL} / \mathrm{min}$ per $1.73 \mathrm{~m}^{2}$. Nonresponders included patients who started dialysis suddenly $(n=7)$ and patients who did not return the survey $(n=39)$. Most of the nonresponders were men (39/46, $84.8 \%$ ), but age, stage of disease and referring renal unit were similar to responders (data not shown). The age and sex of participants closely resembled the national population of incident dialysis patients. ${ }^{25}$

\section{Validity of responses}

Data from all patients $(n=105)$ were used for the main analysis. ${ }^{12} \mathrm{~A}$ secondary analysis involving the 75 patients who answered the practice questions correctly (see survey in Appendix 2) showed no significant differences to the main analysis (data not shown). Five of the seven characteristics (life expectancy, number of visits to the renal unit, travel restrictions, time of day during which dialysis was scheduled and availability of subsidized transport) were significant $(p<0.05)$, and the parameter estimates for all characteristics other than flexibility of the treatment schedule were in the expected direction. The McFadden pseudo $R^{2}$ for our model was 0.50 , which may be considered good. ${ }^{24}$

\section{Preferences and trade-offs}

Figure 1 shows the results of our model. With 105 patients each answering 12 choice sets, we ana- lyzed 1260 choice sets, from which dialysis (option A or B) was chosen $90 \%$ of the time, and conservative care (option C) was chosen $10 \%$ of the time. Six patients chose the conservative care option in all 12 choice sets. The age range of these six patients was 39-82 years, three were men, five did not have private health insurance and were on a low income, four were receiving a pension, and all six lived less than $50 \mathrm{~km}$ from the closest dialysis unit (data not shown).

For the total sample, as the average estimated life expectancy increased, the odds of preferring dialysis to conservative care increased as expected (Figure 1). The odds of preferring dialysis to conservative care also increased as subsidized transport for attending treatments and appointments was made available. When dialysis was offered during the day or evening (compared with only during the day or overnight), the odds of preferring dialysis to conservative care increased. The opportunity to receive dialysis at night (nocturnal dialysis) did not significantly affect treatment preference. As the patients' ability to travel or go on short trips became restricted, the odds of preferring dialysis decreased. Finally, as the number of visits to hospital increased, the odds for preferring dialysis decreased.

Patient age did not significantly affect the preference for dialysis or conservative care when modelled as a continuous variable, nor when age was dichotomized into 65 years and older versus younger than 65 years (Figure 1). Patient sex, type

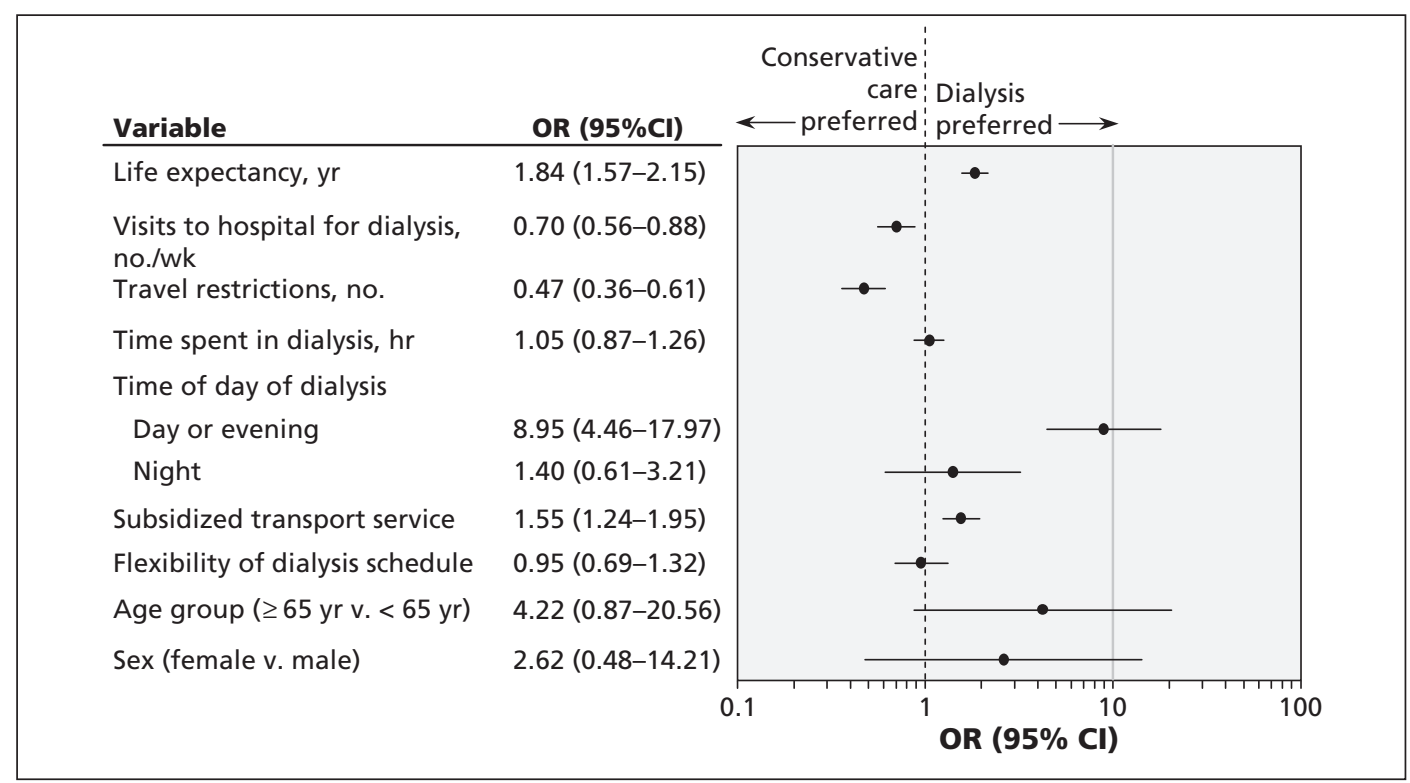

Figure 1: Treatment preferences (dialysis v. conservative care) of 105 patients with end-stage chronic kidney disease. For numeric variables (life expectancy, number of visits to hospital and number of hours of dialysis per treatment), odds ratios correspond to an increase of one unit (i.e., 1 year, 1 visit to hospital per week, 1 hour of dialysis). For ordinal qualitative attributes (travel restrictions, available subsidized transport and treatment flexibility), odds ratios correspond to an increase of one level (e.g., from no subsidized transport to partially subsidized transport, or from partially subsidized to fully subsidized). For the variable "time of day", dialysis during the day was used as the reference group. $\mathrm{Cl}=$ confidence interval, $\mathrm{OR}=$ odds ratio. 
of health insurance, level of education, employment status, distance from home to the dialysis unit, size of household, income, stage of chronic kidney disease or previous kidney transplant did not significantly affect preferences for treatment when modelled as individual covariables. Two-way interactions between sociodemographic variables and treatment characteristics did not improve our model's fit, nor did they alter our conclusions; thus, we did not include them in the final model.

We calculated benefit-to-harm trade-offs between life expectancy and other characteristics (i.e., how much life expectancy patients were willing to give up for an improvement by one level in one of the other characteristics) for characteristics that were statistically significant. Patients were willing to forgo 7 (95\% CI 4-10) months of life expectancy to reduce the number of visits per week to hospital for dialysis by one unit (e.g., from four visits to three). Furthermore, patients were willing to forgo 15 months (95\% CI 11-22) of life expectancy to decrease their travel restrictions by one level (e.g., from "very restricted" to "somewhat restricted").
Patients made specific reference to five of the characteristics investigated in the survey in their written comments: life expectancy, travel, time spent undergoing dialysis, time of day and transport (Table 2). In addition, they identified two sociodemographic factors (age and comorbidity) as influential in their decision-making. Some patients also referred to a perceived losses of freedom and quality of life with dialysis.

\section{Interpretation}

We have highlighted several implications for policy that may be applicable to health systems in other countries with geography, funding, and the provision of renal services that are similar to Australia, such as Canada.

First, dialysis should not be presumed to be the treatment of choice for all patients approaching end-stage kidney disease. Our data suggest that some patients prefer conservative care regardless of the survival benefits afforded by dialysis. For other patients, dialysis was not worth considering if it involved too many visits to hospital or restrictions

Table 2: A selection of written comments from patients with chronic kidney disease from a survey exploring their preferences for treatment

Characteristic of treatment

Comment

\begin{tabular}{|c|c|}
\hline Life expectancy & $\begin{array}{l}\text { "I am bringing up my grand-daughter she is } 8 \text { and I need to stay alive to look after her. She has been with } \\
\text { me since she was } 2 . " \text { - Patient } 86 \text { ( } 60 \text {-year-old man) } \\
\text { "I am due to go onto dialysis in the next } 3 \text { months. As you see- my main choice is to live as long as possible, } \\
\text { no matter what time (commitment) is involved." - Patient } 19 \text { (74-year-old woman) } \\
\text { "Because of my age and otherwise good health, survival time is paramount." - Patient } 82 \\
\text { (63-year-old man) }\end{array}$ \\
\hline Travel & $\begin{array}{l}\text { "Me and my wife have a mission overseas we need to travel all the time, also for } 1-3 \text { months at a time and } \\
\text { this treatment will hold all activities and I'm not sure if I can do that or not." - Patient } 73 \text { (66-year-old } \\
\text { man) } \\
\text { "The main concern for myself is that dialysis does not 'take control' over my life. My wife and I like to go } \\
\text { away for short trips and still want to do that well into the future." - Patient } 21 \text { (64-year-old man) }\end{array}$ \\
\hline $\begin{array}{l}\text { Time spent } \\
\text { undergoing dialysis }\end{array}$ & $\begin{array}{l}\text { "I consider } 12 \text { hours (dialysis) weekly inadequate. Allowing for domestic duties (I live alone) the time for } \\
\text { travelling the } 100 \mathrm{~km} \text { round trip to the closest renal unit tends to rule out } 8 \text { hour dialysis." - Patient } 46 \\
\text { (82-year-old man) }\end{array}$ \\
\hline Time of day & "Home dialysis at night allows time for shopping, car rego [registration] etc." — Patient 46 (82-year-old man) \\
\hline Transport & "Transport to me is a consideration, whether at a small or no cost." - Patient 46 (82-year-old man) \\
\hline Age & $\begin{array}{l}\text { "Had I been younger, my responses would very likely be different. I imagine that my life expectancy is not } \\
\text { great anyway and having dialysis would be quite disruptive." - Patient } 16 \text { (81-year-old woman) }\end{array}$ \\
\hline Comorbidities & $\begin{array}{l}\text { "As I have had a stroke my disability causes problems with haemodialysis as there are circulatory } \\
\text { problems." - Patient } 42 \text { (77-year-old man) } \\
\text { "While I expect to hold my driving licence for some time, being diabetic and } 82 \text { is a consideration...While I } \\
\text { tend to favour home dialysis, changing circumstances could change this (e.g., I have an upstairs unit, so } \\
\text { should I develop stairs problems, I may have to move to a retirement home close to a renal unit)" } \\
\text { - Patient } 46 \text { (82-year-old man) }\end{array}$ \\
\hline Quality of life & $\begin{array}{l}\text { "It is for these reasons that I am hesitating to go on dialysis. Apart from pain, there will no longer be a } \\
\text { quality of life. My answers are based on if I should go on dialysis." Patient } 81 \text { (66-year-old man) } \\
\text { "I think dialysis would be very restrictive to my quality of life. I am very active in my community and also } \\
\text { love to travel and head bush whenever I like. At the moment I have a very unrestrictive lifestyle and want } \\
\text { to keep it that way." - Patient } 83 \text { (67-year-old man) }\end{array}$ \\
\hline
\end{tabular}


on their ability to travel. This evidence suggests that there needs to be effective policy and clinical pathways to support patients who choose not to undergo dialysis. In the United Kingdom, for example, the National Institute for Health and Clinical Excellence pathway for managing chronic kidney disease leads to renal replacement therapy with no option for conservative care. ${ }^{26}$ Thus, better evidence is needed as to the implications of nondialytic management on prognosis and quality of life.

Second, we found that some patients were willing to accept shorter life expectancy to ensure their ability to travel with minimal restrictions. Given that the median age of our study population coincides with the average age of retirement for many people (a period of life during which people often plan to travel), this is not entirely surprising. It is possible that this treatment attribute was a proxy for perceived quality of life. If so, interventions that support a patient's ability to travel may also improve their quality of life on dialysis.

Third, the availability of subsidized transport was an incentive to choose dialysis and was not dependent on the distance between a patient's home and the dialysis centre. The efficient provision of transport for patients receiving dialysis is a continuing problem for renal centres and is an important principle in equity of access to dialysis services, which has been highlighted in the National Framework for Renal Services in the UK and in state renal plans in Australia..$^{21,27}$

\section{Comparison with other studies}

Although there are few studies examining preferences for dialysis compared with conservative care, one large Canadian study involving 584 patients with chronic kidney disease reported that $60 \%$ of participants regretted their decision to start dialysis, and that they had done so to uphold their physician's or family's wishes. ${ }^{28}$ Two observational studies of patients who chose conservative care suggest that they were older than patients who chose dialysis, but the two groups were not significantly different with respect to ethnicity, comorbidity or level of education. ${ }^{29,30}$ Two further studies reported functional impairment, diabetes and low socioeconomic status as determinants for starting conservative care instead of dialysis. . $^{31,32}$

Our study did not find any significant differences in the characteristics of patients with respect to their preferences for conservative care compared with dialysis, which differs from the results of a qualitative study that suggested a distance of more than $35 \mathrm{~km}$ between a patient's home and the dialysis unit may determine whether the patient starts dialysis. ${ }^{33}$

Overall, our results are consistent with studies that use the time trade-off to elicit preferences, whereby patients with end-stage kidney disease are willing to make considerable trade-offs in survival for improved quality of life. ${ }^{34,35}$

\section{Limitations}

Our sample size was powered for main effects only, which may have limited our ability to test for interactions between variables. Because it was not feasible to include all potential characteristics mentioned by patients in our previous research, ${ }^{18}$ we cannot exclude other potential influences on patient choice.

We did not attempt to capture the influence of different dialysis modalities on patient choice, because we felt it would be necessary first to understand the initial important decision about whether to accept dialysis of any type versus conservative care. This critical first question is highly relevant for primary care physicians, even before making a referral to a nephrologist. In addition, because patients were instructed to make their choices under the assumption that a kidney transplant was not possible, our study did not explicitly capture how the option of a possible future transplant might influence their choice. However, with the average wait time for a kidney transplant in Australia between four and seven years, it is very likely that such patients would still face a choice between an initial period of dialysis or conservative care.

We collected data on patients' stated preferences rather than their actual choices, and some data suggest that stated preferences may not always reflect the real choices patients make. ${ }^{14}$

We found significant heterogeneity in the preferences of characteristics from our respondents, which was not explained by the differences in demographic variables such as age, sex, education or employment. In addition, discrete choice analysis assumes that the trade-offs patients are willing to accept between attribute levels are linear. Our results are therefore no substitute for carefully assessing the preferences of individual patients in a clinical setting; however, these results do provide some basis for clinicians to prioritize the issues they discuss with patients.

\section{Conclusions}

The factors most strongly associated with patient preference for dialysis over conservative care in our sample were increased life expectancy, the opportunity to undergo dialysis during the day or evening, and the availability of subsidized transport. Patients in our study who were approaching end-stage kidney disease were willing to trade considerable life expectancy to reduce the burden and restrictions of dialysis. Further research is needed on the decisionmaking of older patients with end-stage disease, particularly in terms of their preferences for differ- 
ent models of renal palliative care. In addition, research is required into preferences for the type and location of dialysis - information that is important for the planning of future renal services.

\section{References}

1. United States Renal Data System 2010 annual data report: Atlas of chronic kidney disease \& end-stage renal disease in the United States. Am J Kid Dis 2011;57(Suppl 1):e1-526.

2. US Cancer Statistics Working Group. United States cancer statistics: 1999-2007 incidence and mortality data. Atlanta (GA) US Department of Health and Human Services, Centers for Disease Control and Prevention and National Cancer Institute. Available: www.cdc.gov/uscs (accessed 2011 June 7).

3. Australian Institute of Health and Welfare. End-stage kidney disease in Australia: total incidence, 2003-2007. Canberra: (Australia); 2001. Cat. no. PHE 143.

4. Murtagh FEM, Marsh JE, Donohoe P, et al. Dialysis or not? A comparative survival study of patients over 75 years with chronic kidney disease stage 5. Nephrol Dial Transplant 2007;22:1955-62.

5. Chandna SM, Da Silva-Gane M, Marshall C, et al. Survival of elderly patients with stage $5 \mathrm{CKD}$ : comparison of conservative management and renal replacement therapy. Nephrol Dial Transplant 2011;26:1608-14.

6. Joly D, Anglicheau D, Alberti C, et al. Octogenarians reaching end-stage renal disease: cohort study of decision-making and clinical outcomes. J Am Soc Nephrol 2003;14:1012-21.

7. Ellam T, El-Kossi M, Prasanth KC, et al. Conservatively managed patients with stage 5 chronic kidney disease — outcomes from a single center experience. Q JM 2009;102:547-54

8. Renal Physicians Association. Shared decision-making in the appropriate initiation of and withdrawal from dialysis. Clinical practice guideline. 2nd ed. Rockville (MD): The Association; 2010.

9. McFadden D. Conditional logit analysis of qualitative choice behaviour. In: Zarembka P, editor. Frontiers in econometrics. New York (NY): Academic Press; 1974. p. 105-42.

10. Lancaster K. A new approach to consumer theory. J Polit Econ 1966;74:134-57.

11. Ryan M, Gerard K. Using discrete choice experiments to value health care programmes: Current practice and future research reflections. Appl Health Econ Health Policy 2003;2:55-64.

12. Lancsar E, Louviere J. Conducting discrete choice experiments to inform healthcare decision making: a user's guide. Pharmacoeconomics 2008;26:661-77.

13. Bryan S, Gold L, Sheldon R, et al. Preference measurement using conjoint methods: an empirical investigation of reliability. Health Econ 2000;9:385-95.

14. Bridges JFP, Brett Hauber A, Marshall D, et al. Conjoint analysis applications in health - a checklist: a report of the ISPOR Good Research Practices for Conjoint Analysis Task Force. Value Health 2011;14:403-13.

15. Davison SN, Kromm SK, Currie GR. Patient and health professional preferences for organ allocation and procurement, end-of-life care and organization of care for patients with chronic kidney disease using a discrete choice experiment. Nephrol Dial Transplant 2010;25:2334-41.

16. Morton RL, Tong A, Howard K, et al. The views of patients and carers in treatment decision making for chronic kidney disease: systematic review and thematic synthesis of qualitative studies. BMJ 2010;340(c112):350

17. Morton RL, Devitt J, Howard K, et al. Patient views about treatment of stage 5 CKD: a qualitative analysis of semistructured interviews. Am J Kidney Dis 2010;55:431-40.

18. Morton RL, Tong A, Webster AC, et al. Characteristics of dialysis important to patients and family caregivers: a mixed methods approach. Nephrol Dial Transplant 2011;26:4038-46.

19. Ansell D, Roderick P, Steenkamp R, et al. UK Renal Registry 12th Annual Report (December 2009): chapter 7: survival and causes of death of UK adult patients on renal replacement therapy in 2008: national and centre-specific analyses. Nephron Clin Pract 2010;115 Suppl 1:c117-44.

20. Polkinghorne K, Livingston B, Dent H, et al. Chapter 5 . Haemodialysis 2010. In: The 33rd annual report 2010 report data to 2009. Adelaide (Australia): Australia \& New Zealand Dialysis \& Transplant Registry; 2010. p. 2-14.

21. New South Wales Department of Health: Statewide Services Development Branch. NSW renal dialysis service plan to 2011. Sydney (Australia): The Department; 2007. p. 1-50.

22. Rose JM, Bliemer MCJ. Constructing efficient stated choice experimental designs. Transp Rev 2009;29:587-617.

23. Australian Bureau of Statistics. 6523.0 - Household Income and Income Distribution, Australia, 2005-06. Appendix 3 Equivalised disposable household income. Canberra (Australia): The Bureau; 2007. Available: www.abs.gov.au/ausstats/abs@ .nsf/Previousproducts/6523.0Appendix32005-06?opendocument\& tabname $=$ Notes $\&$ prodno $=6523.0 \&$ issue $=2005-06 \&$ num $=\&$ view $=$ (accessed 2011 May 23)

24. Hensher D, Rose J, Greene W. Applied choice analysis: a primer. New York (NY): Cambridge University Press; 2005.

25. Grace B, Excell L, Dent H, et al. Chapter 2. New patients commencing treatment in 2009. In: The 33rd annual report 2010 report - data to 2009. Adelaide (Australia): Australia \& New Zealand Dialysis \& Transplant Registry; 2010. p. 2-3.

26. National Institute for Health and Clinical Excellence. NICE pathways — chronic kidney disease overview. London (UK): 2011. The Institute; Available: http://pathways.nice.org.uk/pathways/chronic -kidney-disease\#content=view-node\%3Anodes-renal-replacement -therapy (accessed 2011 May 17).

27. Department of Health. The National Service framework for renal services. part 1: dialysis and transplantation. London (UK): The Department; 2004

28. Davison SN. End-of-life care preferences and needs: perceptions of patients with chronic kidney disease. Clin J Am Soc Nephrol 2010;5:195-204

29. Carson RC, Juszczak M, Davenport A, et al. Is maximum conservative management an equivalent treatment option to dialysis for elderly patients with significant comorbid disease? Clin J Am Soc Nephrol 2009;4:1611-9.

30. Burns A, Davenport A. Maximum conservative management for patients with chronic kidney disease stage 5. Hemodial Int 2010; 14:S32-7.

31. Smith C, Da Silva-Gane M, Chandna S, et al. Choosing not to dialyse: evaluation of planned non-dialytic management in a cohort of patients with end-stage renal failure. Nephron Clin Pract 2003;95:c40-6.

32. Yong DSP, Kwok AOL, Wong DML, et al. Symptom burden and quality of life in end-stage renal disease: a study of 179 patients on dialysis and palliative care. Palliat Med 2009;23:111-9.

33. Visser A, Dijkstra GJ, Kuiper D, et al. Accepting or declining dialysis: considerations taken into account by elderly patients with end-stage renal disease. J Nephrol 2009;22:794-9.

34. Churchill DN, Torrance GW, Taylor DW, et al. Measurement of quality of life in end-stage renal disease: the time trade-off approach. Clin Invest Med 1987;10:14-20.

35. Gorodetskaya I, Zenios S, McCulloch CE, et al. Health-related quality of life and estimates of utility in chronic kidney disease. Kidney Int 2005;68:2801-8.

Affiliations: From the Sydney School of Public Health (Morton, Webster, Howard), the University of Sydney, Sydney; the Department of Renal Medicine (Snelling), Royal Prince Alfred Hospital, Camperdown; Institute of Transport and Logistics Studies (Rose), Faculty of Economics and Business, The University of Sydney, Sydney; Melbourne Health (Masterson), Parkville; and University of Queensland at Princess Alexandra Hospital (Johnson), Woolloongabba, Australia

Contributors: Rachael L. Morton designed the discrete choice survey, coordinated data collection, cleaned and analyzed the data, and drafted and revised the paper; she is guarantor. Paul Snelling assisted with the study design, recruited participants in rural and metropolitan clinics and revised the paper. Angela C. Webster assisted with the study's design and analysis, and revised the paper. John Rose assisted with the discrete choice design and econometric analysis, and revised the draft paper. Rosemary Masterson and David W. Johnson assisted with the survey's design and the recruitment of participants, and revised the draft paper. Kirsten Howard assisted with the overall study design and analysis, and revised all drafts of the paper.

Funding: Rachael Morton is supported through grants from the National Health and Medical Research Council (no. 457281 and no. 571372). David Johnson is supported by a Queensland Government Health Research Fellowship. The funding bodies had no role in the design of the study, the collection, analysis or interpretation of data, the writing of the report or the decision to submit the article for publication.

Acknowledgements: The authors thank the predialysis patients and their caregivers for participating in this study, and Tanya Smolonogov, Jacqui Moustakas, Jenny Best, Jenny de Rossi and Lee Douglas for assisting with the recruitment of participants. 